\title{
Métodos de produção de mudas, distribuição de matéria seca e produti- vidade de plantas beterraba
}

\author{
Vandeir Francisco Guimarães ${ }^{1}$; Márcia M. Echer²; Keigo Minami² \\ ${ }^{1 /}$ UNESP, C. Postal 237, 18.603-970, Botucatu-SP. E-mail: vandeirfg@bol.com.br; ${ }^{2 / E S A L Q, ~ C . ~ P o s t a l ~ 09, ~ 13.418-900, ~ P i r a c i c a b a-S P . ~}$
}

\section{RESUMO}

Comparou-se desenvolvimento de mudas de beterraba (cv. Tall Top Early Wonder), produzidas por diferentes métodos, através da distribuição de matéria seca na planta. Comparou-se os tratamentos $\mathrm{T} 1$ - mudas produzidas em bandejas de 288 células $\left(1,2 \times 10^{-5} \mathrm{~m}^{3}\right)$; $\mathrm{T} 2-200$ células $\left(1,6 \times 10^{-5} \mathrm{~m}^{3}\right) ; \mathrm{T} 3-128$ células $\left(3,2 \times 10^{-5} \mathrm{~m}^{3}\right) ; \mathrm{T} 4$ -128 células $\left(7,2 \times 10^{-5} \mathrm{~m}^{3}\right)$; T5 - semeadura direta e T6 - mudas de raiz nua. Aos 28 dias após a semeadura (DAS), as mudas produzidas em bandejas foram transplantadas para campo, juntamente com mudas de raiz nua (T6). O delineamento experimental foi de blocos ao acaso com quatro repetições. Foram coletadas plantas semanalmente dos 28 aos 98 DAS. Determinou-se a matéria seca das folhas, pecíolos, raízes e da parte aérea e a matéria fresca das raízes. Aos 98 DAS, realizou-se a colheita das raízes comerciais, expressando-se a produtividade em $\mathrm{kg} \mathrm{ha}^{-1}$. Para o tratamento T5, o espessamento da raiz tuberosa começou 42 DAS. Por sua vez, as plantas provenientes dos tratamentos T1, T2, T3, T4 e T6 iniciaram o acúmulo de matéria seca nas raízes a partir dos 56 DAS. Os métodos de produção de mudas não influenciaram significativamente na produtividade da cultura, porém aumentaram o ciclo, quando comparado à semeadura direta. Caso a disponibilidade de área seja fator limitante, a produção de mudas em bandejas é recomendável, sendo indicadas bandejas de 288 células.

\begin{abstract}
Seedlings production and yield of beet plants

Different methods of beet seedling production were evaluated by distributing dry matter on the plants. The experimental design was of randomized blocks with four replications and six treatments: $\mathrm{T} 1$ - seedlings produced in trays of 288 cells $\left(1.2 \times 10^{-5} \mathrm{~m}^{3}\right)$; $\mathrm{T} 2$ 200 cells $\left(1.6 \times 10^{-5} \mathrm{~m}^{3}\right)$; T3 -128 cells $\left(3.2 \times 10^{-5} \mathrm{~m}^{3}\right)$; T4 - 128 cells $\left(7.2 \times 10^{-5} \mathrm{~m}^{3}\right)$; T5 - direct sowing and T6 - bare-root seedlings. The seedlings produced in trays and the bare-root seedlings were transplanted to the field on the $28^{\text {th }}$ day after the sowing (DAS), with spacing of $0.20 \times 0.10 \mathrm{~m}$. Four plants from each treatment were sampled at weekly intervals from the $28^{\text {th }}$ until the $98^{\text {th }}$ DAS. The number of leaves and dry matter content of leaves, petioles, roots and shoots were determined. Storage root fresh matter and medium storage root diameter were determined starting from the $77^{\text {th }}$ DAS. On the $98^{\text {th }}$ DAS 20 plants from each treatment were harvested estimating the productivity in $\mathrm{kg} \mathrm{ha}^{-1}$. Plants from T5 started thicken the storage roots 42 DAS and those from T1, T2, T3, T4 and T6 started to accumulate dry matter in the roots from the 56 DAS. The methods of beet seedlings production did not significantly modify the productivity, however they increased the cycle, compared to the direct sowing. Nevertheless, if the area is a limiting factor in the field, tray-seedling production is recommended, and trays of 288 cells being indicated.
\end{abstract}

Keywords: Beta vulgaris L., trays, sowing.

Palavras-chave: Beta vulgaris L., bandeja, semeadura.

(Recebido para publicação em 15 de agosto de 2001 e aceito em 25 de março de 2002)

\begin{abstract}
A produção de mudas de hortaliças constitui-se em uma das etapas mais importantes do sistema produtivo, influenciando diretamente o desempenho final das plantas nos canteiros de produção, tanto do ponto de vista nutricional quanto no ciclo produtivo da cultura (Carmello, 1995).

Tradicionalmente, a cultura da beterraba (Beta vulgaris L.) tem sido estabelecida por semeadura direta ou por meio do transplante de mudas de raiz nua. No entanto, estes métodos proporcionam campos de cultivo desuniformes em função da má germinação ou do estresse causado pelo transplante. Contrariamente ao que ocorre com outras hortaliças tuberosas, a beterraba adapta-se bem ao transplante. Uma alternativa é a produção de mudas de beterra-
\end{abstract}

ba em bandejas, devido às vantagens que o método proporciona (Filgueira, 2000). Este método viabiliza o cultivo de determinadas espécies que necessitam de maior cuidado na fase de germinação e emergência. Segundo Filgueira (1982), apesar de o transplante de mudas prolongar o ciclo da cultura, tal prática eleva a produtividade e a qualidade do produto final, além de reduzir o consumo de sementes. O uso de bandejas de isopor tem se mostrado eficiente sob vários aspectos, como economia de substrato e de espaço dentro de casa de vegetação, menor gasto com produtos fitossanitários e obtenção de mudas de alta qualidade e elevado índice de pegamento após o transplante (Oliveira et al., 1993). O tamanho do recipiente e o tipo de substrato a serem utilizados são fatores importantes, que influenciam diretamente o desenvolvimento e a arquitetura do sistema radicular (Latimer, 1991), bem como o fornecimento de nutrientes (Carneiro, 1983).

Mudas mal formadas debilitam e comprometem todo o desenvolvimento da cultura, aumentando seu ciclo e levando a perdas na produção. As mudas formadas em sementeiras são transplantadas com raiz nua, sem torrões ao seu redor, sendo muito sensíveis às condições ambientais, podendo apresentar danos no sistema radicular e serem contaminadas por patógenos (Souza \& Ferreira, 1997). $\mathrm{O}$ estresse provocado pelo transplante, quando severo, pode causar a morte da planta estendendo o ciclo da cultura, com reflexos sobre a quantidade e qualidade da produção (Mckee,1981). 
Tabela 1. Número médio de folhas de beterraba (cv. Tall Top Early Wonder), em diferentes métodos de produção de mudas. T1 - Bandejas de 288 células $\left(1,2 \times 10^{-5} \mathrm{~m}^{3}\right)$; T2 - Bandejas de 200 células $\left(1,6 \times 10^{-5} \mathrm{~m}^{3}\right)$; T3 - Bandejas de 128 células $\left(3,2 \times 10^{-5} \mathrm{~m}^{3}\right)$; T4 - Bandejas de 128 células $\left(6,6 \times 10^{-5} \mathrm{~m}^{3}\right)$; T5 - semeadura direta no campo; T6 - Mudas de raiz nua. Piracicaba, ESALQ, 2000.

\begin{tabular}{|c|c|c|c|c|c|c|c|c|c|c|c|c|c|}
\hline \multirow{3}{*}{$\begin{array}{l}\text { Tratamento }- \\
\mathrm{T} 1\end{array}$} & \multicolumn{13}{|c|}{ Dias após a semeadura (DAS) } \\
\hline & \multicolumn{2}{|c|}{28} & \multirow{2}{*}{$\frac{42}{24 a b}$} & \multicolumn{2}{|c|}{49} & 56 & 63 & \multirow{2}{*}{$\begin{array}{c}70 \\
40 a\end{array}$} & \multicolumn{2}{|c|}{77} & \multirow{2}{*}{$\begin{array}{c}\frac{84}{41 a} \\
41\end{array}$} & 91 & \multirow{2}{*}{$\begin{array}{c}98 \\
41 a\end{array}$} \\
\hline & 17 & $b$ & & 27 & $\mathrm{~b}$ & $31 \mathrm{~b}$ & $36 \mathrm{~b}$ & & 36 & $\mathrm{c}$ & & $45 \mathrm{~b}$ & \\
\hline $\mathrm{T} 2$ & 16 & b & $22 b$ & 26 & b & 31 & $38 \mathrm{ab}$ & 38 a & 38 & $\mathrm{bc}$ & $41 \mathrm{a}$ & $41 \mathrm{~b}$ & $41 a$ \\
\hline T3 & 19 & b & $23 a b$ & 27 & $\mathrm{~b}$ & $31 \mathrm{ab}$ & $39 a b$ & $37 \mathrm{a}$ & 38 & $\mathrm{bc}$ & 37 a & $40 \mathrm{~b}$ & $40 \mathrm{a}$ \\
\hline T4 & 20 & b & $23 \mathrm{~b}$ & 29 & $a b$ & $35 a b$ & $41 \mathrm{ab}$ & 39 a & 41 & $a b$ & $44 a$ & $46 \mathrm{~b}$ & $47 \mathrm{a}$ \\
\hline T5 & 28 & & 32 a & 34 & $\mathrm{a}$ & $37 \mathrm{a}$ & $43 a$ & $43 \mathrm{a}$ & 45 & $\mathrm{a}$ & $44 a$ & $55 \mathrm{a}$ & $49 a$ \\
\hline T6 & 28 & & $16 \mathrm{~b}$ & 24 & $\mathrm{~b}$ & $32 a b$ & $38 \mathrm{ab}$ & $37 \mathrm{a}$ & 39 & $\mathrm{bc}$ & $42 a$ & $46 \mathrm{~b}$ & $49 a$ \\
\hline CV (\%) & 7,6 & & 17,07 & 8,7 & & 8,08 & 7,53 & 12,87 & 5 , & 39 & 11,62 & 8,07 & 18,55 \\
\hline
\end{tabular}

*/ Médias seguidas pela mesma letra nas colunas não diferem entre si a 5\% de probabilidade pelo teste de Tukey.

O rendimento da cultura depende da produção de biomassa total e da distribuição de matéria seca entre as partes produtivas e não produtivas da planta (Hole et al., 1983). A produção de matéria seca de uma cultura, quando plantas daninhas, pragas, doenças e condições de solo não são limitantes e quando água e nutrientes estão disponíveis em quantidades suficientes, é função da radiação absorvida pelo dossel, da eficiência média de conversão da radiação absorvida para matéria seca e da partição desta entre as partes úteis e o restante da planta (Charles-Edwards, 1986; Hay \& Walker, 1989).

O presente trabalho objetivou avaliar o efeito de diferentes métodos de produção de mudas de beterraba, no desempenho da planta em condições de campo, através do estudo da distribuição de matéria seca na planta.

\section{MATERIAL E MÉTODOS}

O ensaio foi realizado na ESALQ, em Piracicaba (SP), de maio a agosto de 2000, em Latossolo vermelho eutroférrico. O clima da região é Cwa, tropical úmido, com inverno seco, segundo a classificação de Köppen.

A cultivar de beterraba Tall Top Early Wonder foi submetida aos tratamentos $\mathrm{T} 1$ - mudas produzidas em bandejas de poliestireno expandido com 288 células (célula de 1,2 × 10-5 $\mathrm{m}^{3}$ ); T2 - mudas produzidas em bandejas de 200 células (célula de $1,6 \times 10^{-5} \mathrm{~m}^{3}$ ); T3 - mudas produzidas em bandejas de 128 células (célula de $3,2 \times 10^{-5} \mathrm{~m}^{3}$ ); T4-mudas produzidas em bandejas de 128 células (célula de 7,2 $\mathrm{x} 10^{-5} \mathrm{~m}^{3}$ ); $\mathrm{T} 5$ - semeadura direta no campo e T6 - transplante de mudas de raiz nua, provenientes do desbaste da semeadura direta no campo.

$\mathrm{Na}$ semeadura em bandejas, foram distribuídos dois glomérulos por célula. $\mathrm{Na}$ mesma época, no campo, glomérulos foram distribuídos linearmente numa profundidade aproximada de $15 \mathrm{~mm}$, em canteiros previamente preparados, para compor o tratamento de semeadura direta. Aos 19 dias após a semeadura (DAS), realizaram-se o desbaste (uma planta por célula) e a adubação foliar das mudas produzidas em bandejas [1 $\mathrm{g} \mathrm{L}^{-1}$ de NPK (4-16-8), B $(0,70 \%)]$. As bandejas foram mantidas sob condições de cultivo protegido e irrigação intermitente por microaspersão, sendo os intervalos de irrigação controlados conforme as condições ambientais prevalecentes. Em campo, as mudas foram irrigadas uma vez ao dia, por aspersão e com base nos resultados da análise de solo, não houve necessidade de correção e adubação de plantio.

Aos 28 DAS, as mudas provenientes de bandejas, foram transplantadas, compondo os tratamentos T1, T2, T3 e T4. Nesta ocasião, realizou-se o desbaste das plantas provenientes da semeadura direta (T5), que foram selecionadas e utilizadas para compor o tratamento T6. Os tratamentos foram dispostos em delineamento de blocos ao acaso, com quatro repetições. Cada bloco foi composto por seis unidades experimentais com dimensões de $4 \mathrm{~m}$ de comprimento por $0,8 \mathrm{~m}$ de largura. Utilizou-se espaçamento de $0,2 \mathrm{~m}$ entre linhas e 0,1 $\mathrm{m}$ entre plantas, resultando em 160 plantas por parcela, sendo considerada como área útil as duas linhas internas. Aos 28; $42 ; 49 ; 56 ; 63 ; 70 ; 77 ; 84 ; 91$ e 98 DAS foram realizadas coletas, retirando-se quatro plantas por parcela.

Após cada coleta, as plantas foram levadas ao laboratório, onde determinou-se o número médio de folhas por planta. Posteriormente as plantas foram secionadas em folhas, pecíolos e raízes, acondicionadas em sacos de papel e secadas em estufa com circulação forçada de ar a $65^{\circ} \mathrm{C}$, até atingirem peso constante. Em balança de precisão determinou-se a matéria seca das folhas (MSF), dos pecíolos (MSP) e das raízes (MSR). Obteve-se também a matéria seca total (MST). Os dados de matéria seca foram ajustados em função do tempo (DAS), pela equação exponencial quadrática, que melhor se ajustou, sendo significativo pelo teste $\mathrm{F}(\mathrm{P} \leq 0,01)$.

A partir dos 77 DAS avaliou-se as produções de matéria fresca das raízes (MFR) e o diâmetro médio de raízes (DMR), com auxílio de um paquímetro. Correlacionou-se também MFR $\mathrm{x}$ MSPA; MSR x MFR e MFR x DMR.

Aos 98 DAS, foram colhidas 20 plantas por parcela e estimada a produtividade $\left(\mathrm{kg} \mathrm{ha}^{-1}\right)$. Os dados de produtividade foram submetidos à análise de variância e as médias comparadas pelo teste de Tukey $(\mathrm{P} \leq 0,05)$.

\section{RESULTADOS E DISCUSSÃO}

Verificou-se maior desenvolvimento inicial das plantas obtidas por semeadura direta, quando comparadas às demais (Tabela 1). Gradativamente esta 


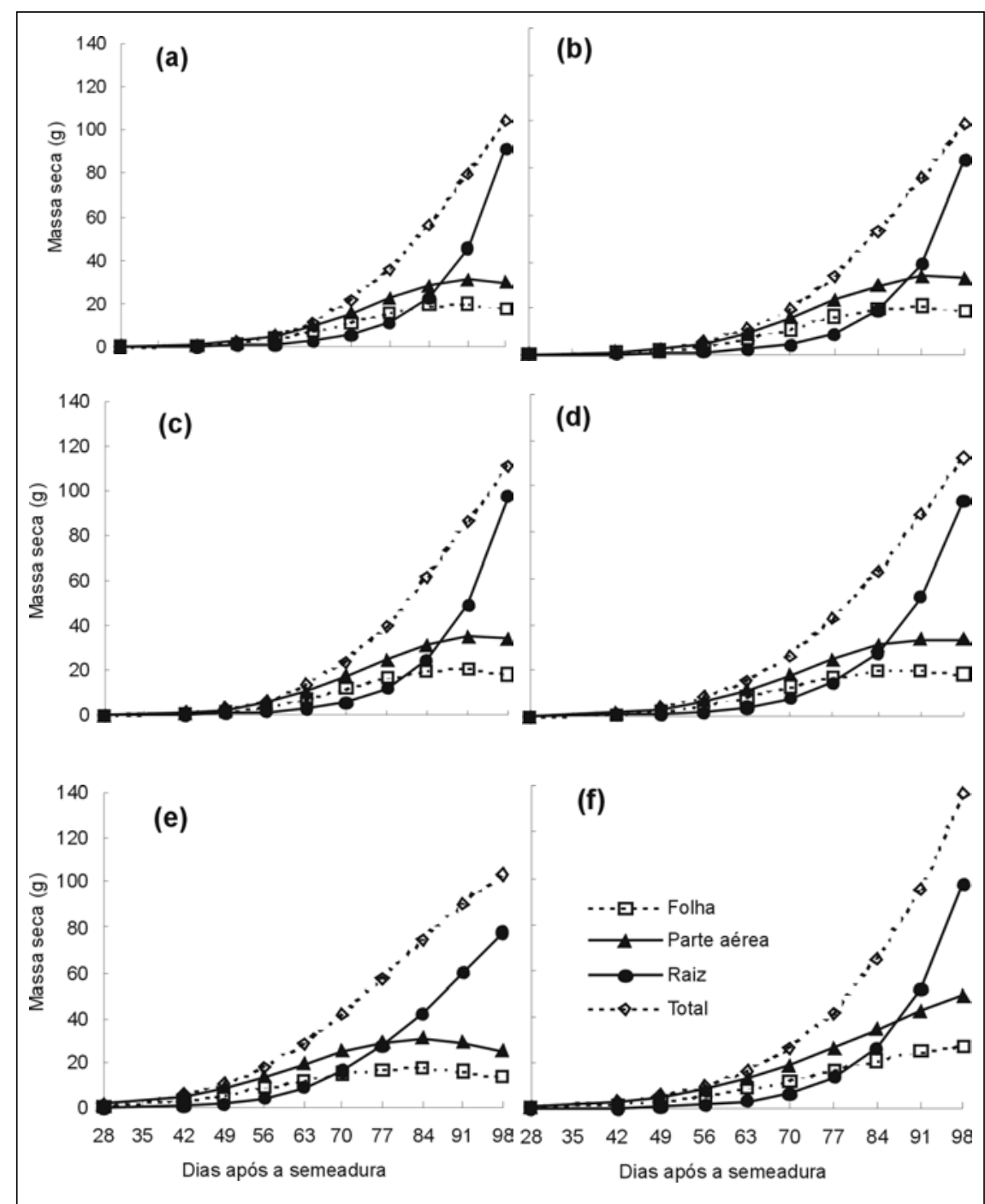

Figura 1. Distribuição de material seca entre diferentes órgãos da planta de beterraba em várias coletas, em função do método de formação de mudas. (a) Bandejas de 288 células $\left(1,2 \times 10^{-5} \mathrm{~m}^{3}\right)$; (b) Bandejas de 200 células $\left(1,6 \times 10^{-5} \mathrm{~m}^{3}\right)$; (c) Bandejas de 128 células $(3,2$ x $\left.10^{-5} \mathrm{~m}^{3}\right)$; (d) Bandejas de 128 células $\left(6,6 \times 10^{-5} \mathrm{~m}^{3}\right)$; (e) semeadura direta no campo; (f) Mudas de raiz nua. Piracicaba, ESALQ, 2000.

diferença foi diminuindo até se igualar estatisticamente nas últimas coletas. Plantas obtidas por transplante de mudas de raiz nua, devido ao grande choque sofrido pelo sistema radicular, apresentaram perda significativa de folhas nas coletas iniciais.

Plantas obtidas de semeadura direta (Figura 1e) apresentaram espessamento visível da raiz tuberosa a partir dos 42 DAS. Com o desenvolvimento, este órgão se tornou fração de importância crescentemente na planta. $\mathrm{O}$ diâmetro da raiz de $18 \mathrm{~mm}$ constituiu $14,57 \%$ da matéria seca aos 42 DAS. Aos 63 DAS, esse órgão representava $31,49 \%$ da matéria seca da planta. A partir dos $84 \mathrm{DAS}$, mente (Figuras 1 a, b, c, d, f). A força de dreno das raízes conduziu a um acúmulo de 87,$81 ; 84,30 ; 87,87 ; 83,39 ; 75,19$ e $71,21 \%$ da matéria seca total da planta neste órgão, para estes tratamentos respectivamente, aos $98 \mathrm{DAS}$, ocasião da colheita final.

Durante o experimento, não foram observadas perdas significativas de matéria seca das folhas por senescência nos tratamentos com produção de mudas em bandejas e raiz nua. Isto mostra que o acúmulo de matéria seca nos órgão de reserva ocorreu em função da fotossíntese corrente no momento deste acúmulo, concordando com resultados obtidos por Benjamin \& Wren (1978) em plantas de cenoura. Porém, para as plantas provenientes de semeadura direta, iniciou-se, a partir de 84 DAS, pequena queda na área e matéria seca foliar. Resultados semelhantes foram mostrados por Nunes et al. (1981) e Nichiporovich (1967), em beterraba açucareira, para plantas com desenvolvimento inicial mais rápido, como ocorreu com foi a semeadura direta. As plantas atingiram mais rapidamente a fase em que se estabelece competição por luz, além da força do dreno do órgão de reserva reduzir a expansão de folhas, porém não foi observada redução no número de folhas (Tabela 1). Segundo Barnes (1979) a distribuição de assimilados pelos órgãos competidores é independente dos fotoassimilados produzidos. Este autor sugere que a competição por luz, particularmente, onde nutrientes e água não são limitantes, teria pequeno efeito no controle da partição de assimilados.

As plantas provenientes de mudas de raiz nua apresentaram maior acúmulo de matéria seca nas folhas e pecíolos, nas coletas realizadas aos 84; 91 e 98 DAS, mantendo o aumento de matéria seca da parte aérea, mesmo com grande alocação de assimilados nas raízes (Figura 1f).

Relacionando os dados de acúmulo de matéria seca da parte aérea com o acúmulo de matéria seca de raízes (Figura 2), verificou-se que houve um grande investimento inicial na parte aérea, logicamente para o estabelecimento dos órgãos responsáveis pela fonte de fotoassimilados. A estabilização do acúmulo de matéria seca na parte aérea 
coincidiu com o acúmulo exponencial de matéria seca nas raízes, que se tornou o grande dreno da planta. Resultados semelhantes foram observados por Nunes et al. (1981) em beterraba açucareira. A matéria seca nas raízes atingiu praticamente o dobro do peso da matéria seca da parte aérea até a última avaliação (98 DAS). Este comportamento foi semelhante para todos os tratamentos, apesar de diferenças quanto ao tempo de ocorrência serem notadas. Estudos com plantas que apresentam raízes de reserva mostram que a taxa de produção de matéria seca pode ser determinada pela taxa de crescimento destes órgãos (Bingham, 1967).

No estudo da correlação entre matéria seca e matéria fresca de raízes, utilizando os dados de todos os tratamentos, nas avaliações de 77 DAS a 98 DAS (Figura 3a), verificou-se uma alta correlação $(r=0,91)$, sendo altamente significativo pelo teste " $\mathrm{t}$ " de Student $(\mathrm{P} \leq 0,01)$. Os resultados mostraram que durante o período de estudo mantevese uma relação constante entre matéria fresca e matéria seca de raízes, não tendo havido uma maior concentração de matéria seca nas coletas finais, indicando que até 98 DAS as raízes se apresentavam em bom estado para colheita. Houve correlação entre o diâmetro médio das raízes em função do ganho de matéria fresca $(\mathrm{r}=0,81)$ sendo altamente significativo pelo teste " $\mathrm{t}$ " de Student ( $\mathrm{P} \leq 0,01)$, quando avaliados os dados de todos os tratamentos (Figura 3b).

Não foi observada diferença estatística entre os tratamentos para produtividade, que foi em média de $55,37 \mathrm{~kg}$ $\mathrm{ha}^{-1}$. Resultado similar foi encontrado por Weston \& Zandstra (1986), que estudando a influência de diferentes tamanhos de bandeja na produção de mudas de tomateiro, verificaram que após o transplante das mudas para o campo, plantas provenientes de mudas produzidas em bandejas com célula de maior volume começavam a produzir mais cedo que aquelas provenientes de células de menor volume, não havendo porém, diferenças entre as produções totais.

Os resultados mostrados e discutidos neste trabalho permitem afirmar que os métodos de produção de mudas avaliados não influenciaram de forma sig-

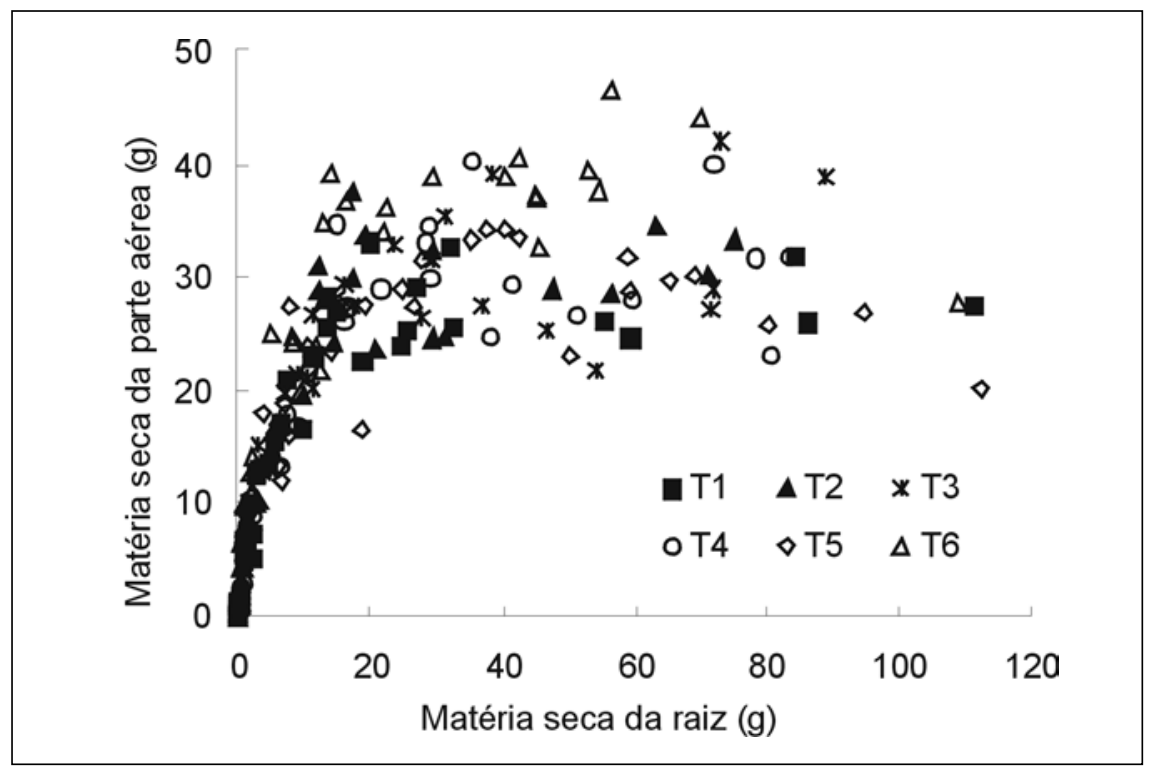

Figura 2. Relação entre material seca da parte aérea e material seca da raiz. Dados de 28 a 98 DAS para todos os tratamentos. $\left(\mathrm{r}=0,70^{* *}\right)$. T1 - Bandejas de 288 células $\left(1,2 \times 10^{-5}\right.$ $\left.\mathrm{m}^{3}\right)$; T2 - Bandejas de 200 células $\left(1,6 \times 10^{-5} \mathrm{~m}^{3}\right)$; T3 - Bandejas de 128 células $\left(3,2 \times 10^{-5}\right.$ $\left.\mathrm{m}^{3}\right)$; T4 - Bandejas de 128 células $\left(6,6 \times 10^{-5} \mathrm{~m}^{3}\right)$; T5 - semeadura direta no campo; T6 Mudas de raiz nua. $(\mathrm{P} \leq 0,01)$. Piracicaba, ESALQ, 2000.

/** Altamente significativo pelo teste " $\mathrm{t}$ " de student $(\mathrm{P} \leq 0,01)$.

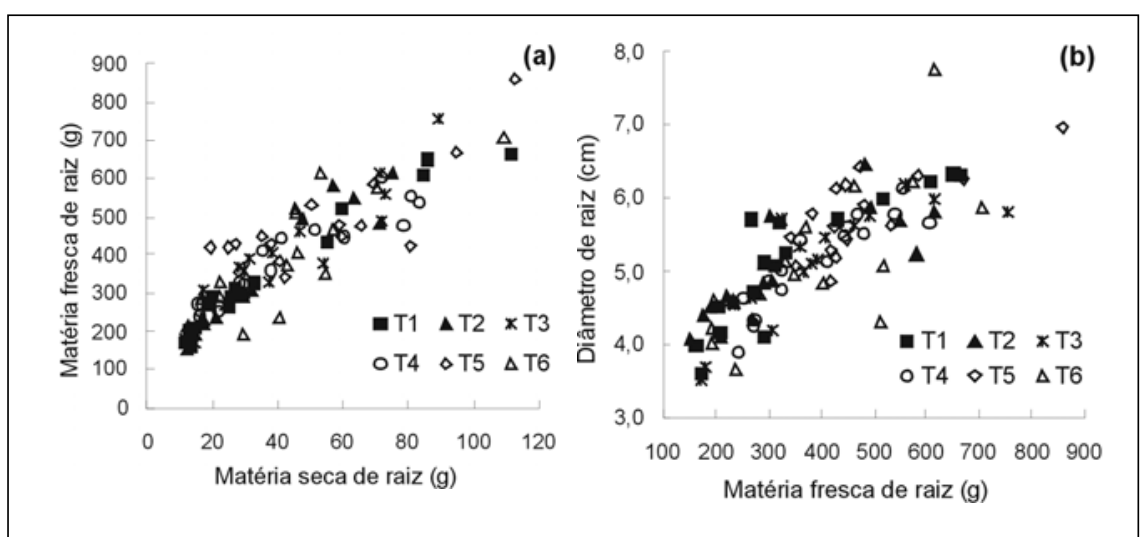

Figura 3. Relação entre (a) matéria fresca de raiz e material seca de raiz de 70 a 98 DAS (r $\left.=0,81^{* *}\right)$. (b) diâmetro médio da raiz e matéria fresca da raiz de 70 a 98 DAS $\left(\mathrm{r}=0,91^{* *}\right)$, para os tratamentos: T1 - Bandejas de 288 células $\left(1,2 \times 10^{-5} \mathrm{~m}^{3}\right)$; T2 - Bandejas de 200 células $\left(1,6 \times 10^{-5} \mathrm{~m}^{3}\right)$; T3 - Bandejas de 128 células $\left(3,2 \times 10^{-5} \mathrm{~m}^{3}\right)$; T4 - Bandejas de 128 células $\left(6,6 \times 10^{-5} \mathrm{~m}^{3}\right)$; T5 - semeadura direta no campo; T6 - Mudas de raiz nua. Piracicaba, ESALQ, 2000.

/ ** Altamente significativo pelo teste " $\mathrm{t}$ " de Student $(\mathrm{P} \leq 0,01)$.

nificativa na produção da beterraba, porém aumentaram o ciclo, quando comparado à semeadura direta no campo. Em situações em que a área é fator limitante, a produção de mudas em bandejas poderia ser viável. Neste caso, como não houve diferenças marcantes entre os tipos de bandejas avaliados, a bandeja de 288 células seria a mais recomendável, por proporcionar maior economia de substrato e espaço em casa de vegetação. Porém estudos de relação custo benefício em cada situação, devem ser realizados para uma tomada de decisão.

\section{AGRADECIMENTOS}

Os autores agradecem a colaboração do Prof. Dr. Ricardo Ferraz de Oliveira do Departamento de Ciências Biológicas da ESALQ/USP, por permitir o uso 
de equipamentos do Laboratório de Plantas Cultivadas Sob Condições de Estresse e dos funcionários do Departamento de Produção Vegetal do Setor de Horticultura, que viabilizaram a condução dos experimentos e coleta dos dados em campo.

\section{LITERATURA CITADA}

BARNES, A. Vegetable plant part relationships. II. A quantitative hypothesis for shoot/storage root development. Annual Botany, v. 43, p. 487-499, 1979.

BENJAMIN, L.R.; WREN, M.J. Root development and source-sink relations in carrot, Daucus carota L. Journal Experimental of Botany, v. 29, n. 109, p. 425-433, 1978.

BINGHAM, J. Investigations on the physiology of yield in winter wheat, by comparisons of varieties and by artificial variation in grain number per ear. Journal Agricultural Science, v. 68, p. 41122, 1967.

CARMELLO, Q.A.C. Nutrição e adubação e mudas hortícolas. In: MINAMI, K. Produção de mudas de alta qualidade em horticultura. São Paulo: T. A. QUEIROZ, 1995. p. 27-37.
CARNEIRO, J.G.A. Variações na metodologia de produções de mudas florestais afetam os parâmetros morfo-fisiológicos que indicam a sua qualidade. Série Técnica FUPEP, v. 12, p. 1-40, 1983.

CHARLES-EDWARDS, D.A. Physiological determinants of crop growth. London: Academic Press. 1986. $161 \mathrm{p}$.

FILGUEIRA, F.A.R. Manual de olericultura: cultura e comercialização de hortaliças. São Paulo: Agronômica Ceres Ltda., 1982. v. 2, 357 p. FILGUEIRA, F.A.R. Novo manual de olericultura: agrotecnologia moderna na produção e comercialização de hortaliças. Viçosa: UFV, 2000, 401 p.

HAY, R.K.M; WALKER, A.J. An Introduction to the physiology of crop yield. UK: Longman Scientific \& Technical. 1989. 292 p.

HOLE, C.C.; BARNES, A.; THOMAS, T.H. SCOTT, P.A.; RANKIN, W.E.F. Dry matter distribution between the shoot and storage root of carrot (Daucus carota L.). I. Comparison of varieties. Annual Botany, v. 51, p. 175-187. 1983. LATIMER, J.G. Container size and shape influence growth and landscape performance of marigold seedling. HortScience, v. 26, p. 124-126, 1991

MCKEE, J.M. Physiological aspects of transplanting vegetables and other crops. I. Factors which influence re-establishment. Horticultural Abstracts, Farnham Royal, v. 51, n. 5, p. 265-272, 1981.
NICHIPOROVICH, A.A. Aims of research on the photosynthesis of plants as a factor in productivity. In: NICHIPOROVICH, A. A. (ed.), Photosynthesis of productive systems. Israel Program for Scientific Translations Ltd., Jerusalem. 1967. 182 p.

NUNES, M.A.; DIAS, M.A.; GASPAR, A.M.; OLIVEIRA, M.D.; PINTO, E.; CARAPAU, A.L. Análise do crescimento da beterraba sacarina em cultura de primavera. Agricultura Lusitana, v. 40, n. 3 , p. $217-240,1981$.

OLIVEIRA, R.P.; SCIVITTARO, W.B.; VASCONCELLOS, L.A.B.C. Avaliação de mudas de maracujazeiro em função do substrato e do tipo de bandeja. Scientia Agrícola, v. 50, n. 2, p. 261-266, 1993.

SOUZA, R.J.; FERREIRA, A.A. Produção de mudas de hortaliças em bandejas: economia de sementes e defensivos. A lavoura, São Paulo, n. 623, p. 19-21, 1997.

WESTON, L.A.; ZANDSTRA, B.H. Effect of root container size and location of production on growth and yield of tomato transplant. Journal of the American Society for Horticultural Science, v. 111, n. 4 , p. 498-501, 1986. 